\title{
Lipoma vulvar gigante
}

\section{Giant vulvar lipoma}

Miguel A. Ramírez-Macías', Benjamín Álvarez-García², Jorge A. Malpica-Del Rayo², Itzel Reyes-de la Garza², Juan Piñeiro-Díaz y Julio C. López-Valdés 3,4,5*

${ }^{1}$ Departamento de Ginecoobstetricia, Hospital Regional de Río Blanco, Río Blanco, Veracruz; ${ }^{2}$ Departamento de Ginecoobstetricia, Hospital General de Martínez de la Torre, Martínez de la Torre, Veracruz; ${ }^{3}$ Universidad Autónoma de Tamaulipas, Facultad de Medicina de Tampico Dr. Alberto Romo Caballero, Tampico, Tamaulipas; ${ }^{4}$ Cognitive Science, S.A., Ciudad de México; ${ }^{5}$ Departamento de Cirugía General, Hospital Regional de Río Blanco, Río Blanco, Veracruz. México

\section{Sr. Editor:}

Los lipomas son tumores mesenquimatosos benignos, compuestos de células adiposas maduras, generalmente asintomáticos y de crecimiento lento. Suelen verse en individuos obesos y de sexo femenino, en la espalda alta, las áreas proximales de las extremidades y el cuello. Su situación vulvar es infrecuente $^{1,2}$. A continuación presentamos el caso de una mujer joven con una tumoración de gran tamaño en el área genital, el cual concuerda con un lipoma vulvar.

Se trata de una mujer de 23 años que inició hace 5 años con una tumoración semisólida, de $2 \mathrm{~cm}$, indolora, de aparición espontanea, en el labio mayor derecho, que fue tratada como bartholinitis y quiste de la glándula de Bartholin, sin mejoría.

En la exploración física se observó una tumoración dependiente del labio mayor derecho de $51 \mathrm{~cm}$ de alto y $30 \mathrm{~cm}$ ancho, con zonas sólidas y reblandecidas. Se realizó tomografía simple, que reportó una lesión sólida avascular dependiente del labio mayor derecho, lobulada. Se decidió programar intervención quirúrgica electiva. Se realizó incisión en huso y mediante disección roma se identificaron las estructuras correspondientes al pedículo vascular. Tras realizar hemostasia se procedió a la exéresis completa de la tumoración, con posterior plastia vulvar. El reporte anatomopatológico fue concordante con lipoma (Fig. 1).

Si bien los lipomas representan el $1 \%$ de los tumores benignos, el origen en la región vulvar es infrecuente; existen cerca de 100 reportes aislados ${ }^{2,3}$. Dentro del área genital, su localización más común es el labio mayor derecho, con una etiología traumática subyacente. Como ocurrió en esta paciente, pueden diagnosticarse erróneamente como enfermedades de las glándulas de Bartholin o hernias inguinales ${ }^{1-4}$.

\section{Conflicto de intereses}

Los autores declaran no tener ningún tipo de conflicto de intereses.

\footnotetext{
Correspondencia:

*Julio C. López-Valdés

Pedro J. Méndez 811

Col. Cascajal

Fecha de recepción: 11-04-2020

C.P. 89280, Tampico, Tamaulipas, México

E-mail: jc.lopz@live.com

Fecha de aceptación: 26-04-2020

DOI: $10.24875 /$ CIRU.20000311

Cir Cir. 2021;89(5):694-695

Contents available at PubMed www.cirugiaycirujanos.com 0009-7411/@ 2020 Academia Mexicana de Cirugía. Publicado por Permanyer. Este es un artículo open access bajo la licencia CC BY-NC-ND (http://creativecommons.org/licenses/by-nc-nd/4.0/).
} 

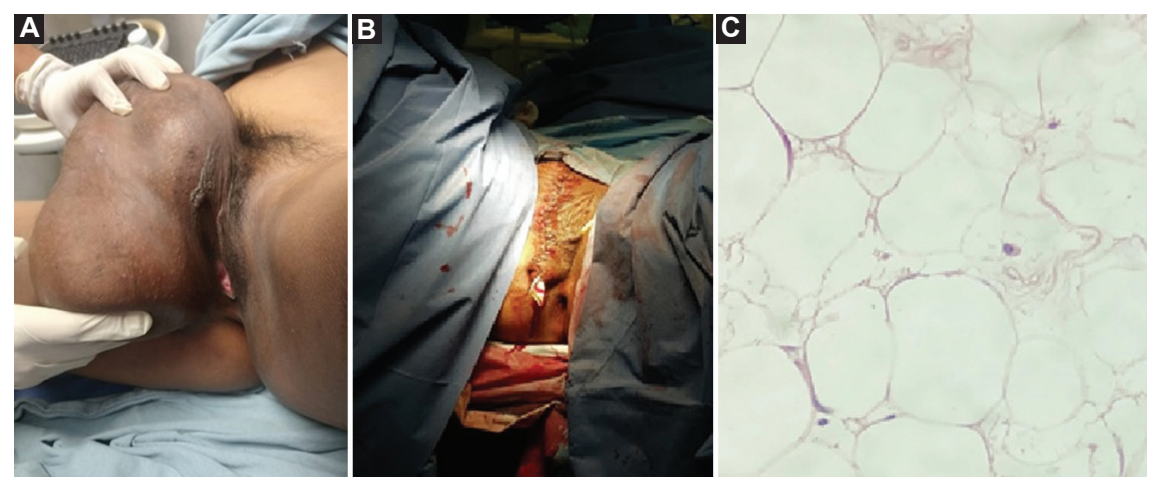

Figura 1. A: aspecto macroscópico del lipoma vulvar. B: plastia vaginal tras la exéresis del lipoma gigante. C: laminillas anatomopatológicas que muestran adipocitos maduros organizados en lóbulos separados por tabiques fibrosos (tinción de hematoxilina y eosina).

\section{Responsabilidades éticas}

Protección de personas y animales. Los autores declaran que los procedimientos seguidos se conformaron a las normas éticas del comité de experimentación humana responsable y de acuerdo con la Asociación Médica Mundial y la Declaración de Helsinki.

Confidencialidad de los datos. Los autores declaran que han seguido los protocolos de su centro de trabajo sobre la publicación de datos de pacientes.

Derecho a la privacidad y consentimiento informado. Los autores han obtenido el consentimiento informado de los pacientes y/o sujetos referidos en el artículo. Este documento obra en poder del autor de correspondencia.

\section{Bibliografía}

1. Reda A, Ihab G. Vulvar lipoma: a case report. Rev Bras Ginecol Obstet. 2018;40:647-9.

2. Gámez-Ricardo JC, Velázquez-Socorro Z, Durán-Rodríguez Y. Gran lipoma vulvar. Presentación de caso. CCM. 2016;20:834-9.

3. Coronil-Belloso P, Fariña-Pérez LA, Picurelli-Oltra L, Perán-Teruel M, Lorenzo-Lorenzo D, Ares-Rodríguez X, et al. Lipoma vulvar gigante. Actas Urol Esp. 2013;37:594-5.

4. Oh JT, Choi SH, Ahna SG, Kimb MY, Yang WI, Han SJ. Vulvar lipomas in children: an analysis of 7 cases. J Pediatr Surg. 2009;44:1920-3. 